\title{
Ensinar e aprender com "professores-educandos": o PIBID de ciências sociais da UFRN em destaque
}

\section{Teach and learn with "teachers-students": the PIBID of social sciences of UFRN in focus}

Dannyel Brunno Rezende ${ }^{11}$

\begin{abstract}
Resumo
A nossa proposta tem por objetivo discutir as experiências educacionais vivenciadas por professores da rede pública do estado do RN no Programa Institucional de Bolsas de Iniciação à Docência da Universidade Federal do Rio Grande do Norte (PIBID/UFRN). Essas experiências se inserem na possibilidade do ensinar e aprender constantes, baseadas no diálogo com estudantes de Ciências Sociais da UFRN, futuros professores de Sociologia. Busca-se não apenas relatar as experiências docentes, mas trazer à tona as orientações surgidas ao longo de toda aprendizagem. Metodologicamente a feitura desse artigo harmoniza teoria e prática enquanto pesquisa científica: contempla uma vasta bibliografia, com ênfase no pensamento do educador Paulo Freire e faz uso de informações empíricas recolhidas por meio de pesquisas etnográficas sobre a escola, a disciplina de sociologia, diálogos com os professores-educandos, informações sobre o programa (PIBID), registros fotográficos, entre outros.
\end{abstract}

Palavras-chave: Ensinar e aprender, PIBID, Sociologia, Paulo Freire.

\section{Abstract}

The present proposal aims to discuss the educational experiences of teachers of the public network of the state RN in the Institutional Program of Scholarship Initiation to the Teaching of the Federal University of Rio Grande do Norte (PIBID / UFRN). These experiences are part of the possibility of teach and learn constant, based on the dialogue with students of Social Sciences of UFRN, future teachers of Sociology. It seeks not only to report the teaching experiences, but also the orientations that have emerged throughout the learning process. The methodology seeks to reconcile theory and practice. Thus, the article includes a large bibliography, with emphasis on the thought of the educator Paulo Freire and makes use of empirical information collected through ethnographic research on the school, the discipline of sociology, dialogues with the teacher-students, information about the program (PIBID), photographic records, among others.

Keywords: Teach and learn, PIBID, Sociology, Paulo Freire.

${ }^{11}$ Programa de Pós-Graduação em Ciências Sociais UFRN (Doutorando); ORCID: https://orcid.org/ooooo003-2699-0076; Email: dannyel.rezende@yahoo.com. 
Nunca nos perguntam sobre o que queremos aprender. Pelo contrário, sempre dizem o que a gente deve estudar ${ }^{12}$ (Paulo Freire).

\section{Introdução}

As experiências aqui delineadas buscam expor e analisar, ainda que sucintamente, saberes educacionais vivenciados em um diálogo permanente entre a teoria e a prática docente, entre o aprendizado teórico no Programa Institucional de Bolsas de Iniciação à Docência (PIBID) e o aprendizado teóricoprático nas Escolas, entre a universidade e as instituições educacionais parceiras do programa. Ensinar a ser professor não é tarefa fácil, pois demanda diversos saberes, a exemplo da compreensão que a educação é uma forma de intervenção no mundo, o reconhecimento de sermos condicionados e a convicção de que a mudança é possivelcomosabiamente foram elencados por Paulo Freire (1996), em sua "Pedagogia da autonomia".

Longe de tentar recriar as orientações de Freire em seu livro, a nossa intenção é de bater as experiências educativas vivenciadas por professores da rede pública do estado do Rio Grande do Norte no PIBID da UFRN durante os últimos três anos (2014-2016). Pensamos que essas experiências, pelas metodologias estimuladas, recobraram de maneira viva os ensinamentos de Paulo. São experiências realizadas dentro do programa e em parcerias com as escolas públicas do RN, com foco ao ensino de futuros professores de sociologia, graduandos em Ciências Sociais na Universidade Federal do Rio Grande do Norte, os quais têm nelas as suas primeiras experiências de ser professor.

A escola pública é a escola da maioria dos brasileiros que só podem contar com ela, é a "escola popular", que Freire a entendia como "escola cidadã" (GADOTTI, 2007). Por isso mesmo que as experiências que relatamos aqui ganham, em certa medida, um viés de experiência popular, de docência que valoriza a escola pública porque nelase ensina e se aprende com as massas, se

\footnotetext{
12 A propósito da falta da prática do diálogo, Paulo Freire, em conversa com Sérgio Guimarães, cita o questionamento de um aluno em uma comunidade eclesial de base na periferia de Belo Horizonte. Cf. (FREIRE; GUIMARÃES, 2003, p. 94).
} 
cresce enquanto cidadão e a faz crescer como instituição pública ${ }^{13}$. A experiência do programa da universidade é também popular, porque acontece num contexto de políticas públicas do governo do Partido dos Trabalhadores (PT) ${ }^{14}$, voltadas para a valorização da docência e da escola pública. Desse modo, nada mais necessário do que o resgate de alguns princípios Freireanos no campo da licenciatura, o que o programa tem conseguido realizar.

Em sintese, tentamos evidenciar um pouco do que já foi dito, isto é, expor as experiências de ensinar que percorreram as vivências no programa, na universidade, com as orientações de reuniões de grupos e reuniões gerais, necessárias ao saber formal e/ou teórico, interligando-as às vivências nas escolas, estas voltadas às orientações práticas do processo constituinte de ser professor.

Esse diálogo se deu em ciclo contínuo de teoria-prática,o qual resultou em um aprendizado mais profundo da docência. Desse processo, todos aprenderam, a exemplo de resultados importantes, expressos em princípios que foram elencados logo mais à frente,para uma prática docente mais respeitosa do aluno e do conhecimento. São, portanto, experiências paulofreireanas estimuladoras de uma prática educativa edificadora de sujeitos. Por isso, o ato de ensinar a ser professor, por meio do programa, foi também um ato enriquecedor de aprender.

\section{Metodologia}

A nossa metodologia de construção do trabalho, enquanto atividade científica, concilia duas linhas principais: uma teórica e outra prática. Assim, fundamentamos as nossas reflexões teóricas, substancialmente, nas contribuições do educador Paulo Freire (1986; 1996; 2003; 2005; 2006; 2011; 2013),ao mesmo tempo em que mantivemos diálogos com autores como

\footnotetext{
13 Para conhecer um pouco mais do perfil da escola pública (educadores, educandos, funcionários, entre outros) na qual foi desenvolvida as atividades do PIBID, conferir, como exemplo, (ALMEIDA et al, 2014; REZENDE, 2016; SILVA; SOUZA; REZENDE, 2015).

14 O PIBID faz parte de um conjunto de políticas públicas desenvolvidas pelo Ministério da Educação e Cultura do Governo Federal(MEC) com o objetivo de melhorar a educação no Brasil, tanto no ensino superior como no ensino básico. Exemplos de outras políticas estimuladas pelo governo são: FIES, PROUNI, ENEM/SISU, PRONATEC, Ciências sem fronteiras, entre outros.
} 
Boaventura de Sousa Santos (2002; 2006;2008), Edgar Morin (2000), Vandana Shiva (2003), Gayatri Spivak (2010).Já do ponto de vista do conhecimento prático, nosso relato se sustenta nas vivências institucionais docentesque foram recobradas pelo pensamento e respaldadas nos registros etnográficos das escolas fundamentados, sobretudo, nas reflexões de Cláudia Fonseca (1999), Maurício de Souza (2006), Amurabi Oliveira (2013)e da disciplina de sociologia, nas atas de reuniões do PIBID/CS, nos relatórios semestrais(2014-2016) que eram enviados à coordenação geral do Programa na universidade, nos diálogos com os professores-educandos, em publicações de trabalhos feitas pelos seus membros sobre o programa (ALMEIDA et al, 2014; REZENDE, 2016; SILVA; SOUZA; REZENDE, 2015), nos registros fotográficos das escolas (Cf:: Blog do PIBID/Ciências Sociais: http://pibidcsufrn.blogspot.com/), entre outros.

\section{Espaços de formação docente: o PIBID de ciências sociais da UFRN e as escolas parceiras}

O PIBID é uma proposta do Ministério da Educação e Cultura (MEC), junto à Coordenação de Aperfeiçoamento de Pessoal de Nivel Superior (CAPES) do Governo Federal, que incentiva os alunos das licenciaturas das Universidades Federais para que tenham uma melhor formação profissional voltada à Educação Básica, inserindo-os na realidade da escola e estimulando-os à participação em atividades formativas, bem como busca capacitá-los cada vez mais ao exercício docente.

Nesse contexto, dentre os vários subprojetos do PIBID está o de Ciências Sociais da UFRN (PIBID/CS), atualmente inserido nas escolas estaduais do Rio Grande do Norte em Natal: Professor Anísio Teixeira, Atheneu NorteRiograndense e Berilo Wanderley. Escolas essas selecionadas conforme importância e viabilidade prática de execução do programa no estado. O projeto conta com a participação de cinco professores-educadores (Supervisores Professor Ms. Augusto Vieira, Professor Ms. Dannyel Rezende e Professor Ms. 
Gustavo Petrovich e Coordenadores - Professora Dra. Ana Patrícia Dias e Professor Dr. Douglas Araújo) e 32 professores-educandos (Bolsistas) ${ }^{15}$.

A Escola Estadual Professor Anísio Teixeira, fundada em 1974 e localizada no bairro comercial de Petrópolis, se caracteriza por ser conhecida por seu ensino compromissado e por sua localização na cidade, em frente à "Praça Cívica de Natal". É uma instituição de grande porte que funciona nos três turnos do Ensino Médio, abrigando algo em torno de 1600 alunos de todas as zonas da cidade e uma equipe escolar de 97 trabalhadores, além de uma razoável estrutura física, com prédio conservado, salas de aulas, refeitório, biblioteca e outros mais equipamentos.

O Colégio Estadual do Atheneu Norte-rio-grandense, localizado também em Petrópolis, se destaca por ser considerado a segunda mais antiga instituição escolar brasileira,_com fundação em 1834 - a mais antiga é o Ginásio Pernambucano de 1825 (CASCUDO, 1961). Possui um prédio histórico tombado pelo governo e em formato de um "X". Recentemente reformado e com uma grande estrutura física,o colégio conta com cerca de 1200 alunos (de toda Região Metropolitana) nos turnos Matutino e Vespertino, nas três séries do Ensino Médio e uma equipe de profissionais em torno de 72 trabalhadores entre professores, administradores, funcionários, entre outros.

A Escola Estadual Berilo Wanderley, por sua vez, está localizada no conjunto Pirangi, bairro Neópolis, Zona Sul da cidade. Fundada em 1984, ficou conhecida por ser uma instituição modelo de magistério e passou a oferecer no seu turno matutino o ensino fundamental, ampliando-se, a partir de 1990, para o Ensino Médio nos turnos vespertino e Noturno. Caracteriza-se por ser uma instituição de médio porte com uma boa infraestrutura em salas, biblioteca, quadra poliesportiva, refeitório, entre outros. Apresenta algo em torno de 1300 alunos, a sua maioria do próprio bairro e um quadro aproximado de 70 trabalhadores entre professores, gestores e demais funcionários.

\footnotetext{
15 Essas terminologias "professor-educador e professor-educando" são adaptações especificas feitas por nós a partir da compreensão geral que temos da linguagem Freireana ("educador e educando"), não se trata, portanto, de construção própria do autor Paulo Freire.
} 
O subprojeto de CS está organizado em reuniões semanais, por subgrupos e reuniões por escolas, quinzenalmente realizadas e em alternância, isto é, na semana em que se realiza reunião por subgrupo não se realiza por escola, alternando-se seguidamente. Há, também, as reuniões gerais, que acontecem às sextas-feiras pela manhã, nas quais se debate assuntos de interesse de todos. Os subgrupos estão divididos em: "Leituras Sociais", que pretende oferecer um melhor suporte na leitura e escrita voltada para a Sociologia; "Teatro do Oprimido", que têm como características o exercício da criatividade e a consciência do corpo; e o subgrupo "Imagem" cujo objetivo é analisar e formar um olhar crítico sobre as imagens, criando, de modo geral, debate em torno de questões que sejam relevantes à sociologia (ALMEIDA, 2014).

O PIBID/CS objetiva construir uma prática docente permanente que dialogue com a realidade das escolas. Pensando em uma formação cada vez mais consistente, o programa possibilita aos professores-educandos uma importante imersão em sala de aula para que entrem, desde o início de sua profissionalização, em contato com o universo educacional básico, articulando teorias e práticas e promovendo trocas de experiências com os alunos e profissionais das escolas. É um destacado incentivo à prática docente direcionada ao campo do Ensino Médio, melhorando a qualidade da formação de futuros professores; possibilitando à educação novos caminhos para pensar a formação docente na universidade e investindo na escola pública, ao tentar transpor o gigantesco "muro" que a separa do meio acadêmico, como se fossem instâncias produtoras de saberes não relacionais (ALMEIDA, 2014).

\section{Diálogos}

Ensinar e aprender são processos concomitantes do ofício de ser professor. $\mathrm{O}$ ato de educar é sempre um ato de aprender. É nesse processo que ensinando, aprende-se a ensinar e que ensinando, aprende-se a dialogar, pois não há ensino e nem aprendizagem sem o diálogo e essa é uma das principais lições de Freire para aqueles que assumem a docência em abertura, que a veem 
como um processo epistemológico crítico, criador e contínuo. Ensinar e aprender só são possíveis no diálogo com o outro, no contexto e no reconhecimento da limitação histórica do ser que aprende.

O diálogo, nesse sentido, não é para Freire simplesmente técnica como o "ir e vir", é condição essencial da própria aprendizagem humana: "algo que pertence a própria natureza do ato de conhecer" (FREIRE; GUMARÃES, 2011). Como estrutura democrática e construtiva de saber crítico-reflexivo, o diálogo é percebido como uma relação horizontal de A com B, nasce de uma matriz crítica e gera criticidade, faz o exercício da comunicação. "Comunicar-se", nesse sentido, é sempre compreensão e atitude diferente de "comunicado", uma vez que aquele é, para Freire (2006), essencialmente relação dialógica e este, relação monológica entre interlocutores, não propiciando a criticidade do homem.

Centrados, então, na metodologia do diálogo como diretriz freireana para as nossas atividades acadêmico-escolares, as reuniões realizadas no programa buscavam dar maior consistência a formação docente. Dessa maneira, nos encontros semanais de grupos, ocorridos às quintas-feiras, o ambiente construído prezava pelo contato direto professor-educador e professoreducando. Esse espaço se constituía como sendo essencial para a formulação daquilo que, tal vez, seja de maior significância para a formação dos futuros professores em sociologia, isto é, os saberes necessários à prática docente nas escolas.

Falamos, aqui, de um conjunto de saberes dados pelo aprendizado técnico do planejamento escolar, que em nosso caso, fundamentados no sequenciamento de aulas, possibilitou o encontro direto dos professoreseducandos com a realidade docente ao transformar a sua experiência numa prática ainda mais rica. Assim, uma das principais mudanças dentro do programa foi substituir, em 2014, o plano tradicional de aula pela sequência didática, isso significou uma docência mais afinada com a formação real do professor, como veremos logo à frente. Além disso, priorizamos o debate pedagógico, com a secundarização de aulas expositivas e ênfase em aulas mais participativas com o 
uso, por exemplo, de dinâmicas de grupos em sala de aula, de tecnologias, atividades de leituras, entre outras.

Nessas reuniões desenvolvíamos também estudos específicos nas áreas de leitura, imagem e teatro, no qual, em cada subgrupo, procurávamos instrumentalizar um desses saberes para a sala de aula com o seu posterior compartilhamento nas reuniões gerais. Isso era feito por meio de leituras de textos, filmografias, livros, etc. ${ }^{16}$. Frizamos as orientações voltadas para a prática etnográfica como forma de conhecer a realidade escolar e adentrar em seus desafios e potencialidades (FONSECA, 1999; SOUZA, 2006; OLIVEIRA 2013). E, finalmente, acentuamos, por sua importância, o debate e as reflexões sobre as aulas ministradas nas escolas. Debate feito em ciclos de diálogos, mediados pelos professores-educadores, como forma de autoavaliação e avaliação em grupo, bem como sugestão de potencialização pedagógica das reuniões.

Complementando esta realidade, nas reuniões gerais às sextas-feiras, os encontros com todos os presentes (professores-educadores e professoreseducandos), possibilitavam-nos o debate geral das atividades semanais e as trocas das experiências/saberes de todos, ampliando a formação docente, sobretudo, no fazer ver ou no analisar a docência de modo geral. A pauta de discussão contemplava, quase sempre, informes gerais sobre o programa e a universidade, os desafios da docência no Ensino Médio e Ensino Superior, com ênfase no debate sobre as experiências docentes nas escolas e a compreensão de textos e filmografias agendadas. Essas reuniões contribuíam para a socialização dos conhecimentos que estavam se fazendo e o seu enriquecimento teórico, bem como insurgia como espaço de centralização e unidade das tomadas de decisões que envolveria as atuações nas escolas.

\footnotetext{
${ }^{16}$ Nos estudos sobre leitura destacamos principalmente Paulo Freire, ao que se refere aos diferentes livros já citados ao longo deste texto. Por outro lado, também era realizada pelo subgrupo a leitura de obras literárias, como o clássico Machado de Assis, entre outros. No debate sobre imagens diversos trabalhos foram elencados, como exemplos, citamos principalmente Rosália Duarte (2006), Roseli Silva (2007), José de S. Martins (2011). Para o teatro a referência essencial do subgrupo e da qual partia os exercicios era Augusto Boal (2005) com o teatro do oprimido.
} 
Era, porém, no interior da escola que a prática docente tomava vida ${ }^{17}$. Nesse sentido, é importante destacar que os professores antes de atuar nas escolas a conhecessem. Foi assim que se deram as visitas na escolas ou, como ficou registrado, a "pesquisa etnográfica", a qual tinha como objetivo o conhecimento do universo escolar desde a comunidade ao entorno até o interior da sala de aula. Por meio desta atividade os bolsistas faziam o reconhecimento da escola através do registro de imagens e informações conseguidas em entrevistas com a direção, coordenação, professores, servidores e alunado. Essa atividade se iniciava a partir do momento que o professor-educando se tornava membro do grupo e se prolongava com as intervenções na escolas, pois possibilitavam momentos de ampliação do conhecimento até as intervenções em sala de aula, que eram momentos também de realização etnográfica.

Para a realização das experiências docentes, por sua vez, era necessário o planejamento. Feito isso, abria-se espaço para o ministrar das aulas. A ideia norteadora era que os professores-educandos se empenhassem para elaborar suas aulas, pô-las em prática, dialogar com os alunos, construir ou ressignificar metodologias, elaborar atividades e avaliações, mas acima de tudo, pudessem perceber o ato de ensinar como uma totalidade complexa, um encadeamento de saberes, contextos e situações relacionais.

Dessa experiência não nos resta dúvida que a opção pela sequência didática foi especialmente favorável à docência, pois ela permitiu ao professoreducando uma maior permanência na sala de aula, tornando-o conhecido pelos alunos e não um professor visitante favoreceu a construção de vínculos dialógicos professor-aluno, possibilitando uma visão de retomada de conteúdos ou imbricamentos das suas aulas (não aulas ministradas de maneira esporádica e/ou desconectadas), possibilitando ao docente o alongamento de sua experiência prática e potencializando o seu aprendizado formacional, dado que com o contato prologando as mais diversas situações de sala, os desafios educacionais tendem a aparecer ao professor.

17 Para um relato mais detalhado sobre a atuação dos "pibidianos" na escola cf.: (ALMEIDA et al, 2014; REZENDE, 2016; SILVA; SOUZA; REZENDE, 2015). 
Assim, a prática docente trouxe à tona situações ainda não vivenciadas pelos professores-educandos, fazendo com que eles procurassem soluções para os diversos problemas surgidos no âmbito da sala de aula. Desafios que vão desde a quebra de rotinas na escola, por diversos motivos - como a falta de água, merenda escolar, reunião de professores de última hora - às mudanças no calendário escolar - em virtude de paralisações por protestos, eventos inesperados, feriadões, etc., possibilitaram a eles maior realidade à prática docente. A escola viva apareceu diante de seus olhos, a escola popular como Freire sempre acentuou, a escola pública com os seus desafios cotidianos para o aluno e para o professor. Foi essa a escola que eles se depararam e vivenciaram as suas angústias. Aprenderam a ministrar aulas em um contexto real de docência.

Dessa forma, foi no chão da escola que os professores-educando puderam, pela primeira vez, encarar um público e falar para todos, enfrentando os seus medos e timidez (FREIRE, 2013), encararem as dificuldades de debater com os discentes sobre os conteúdos sociológicos, nas suas diversas possibilidades ideológicas, insurgindo-se contra as "monoculturas da mente" (SHIVA, 2003), articular saberes diversos na sala de aula como religião, senso comum, ciência, entre outros, em uma verdadeira "ecologia dos saberes" (SANTOS, 2008), fugirem às "violências epistêmicas" (SANTOS, 2006; SPIVAK, 2010) na relação professor-aluno, identificar, dentro de suas limitações de experiência docente, as invisibilidades ou ausências no interior da escola e da sala de aula e conferir importância ao diálogo (FREIRE, 2005; 2006) como ferramenta para a construção do saber educacional. Isso tudo, além do aprendizado teórico, específico da docência, relacionados ao conteúdo, à orientação do aluno, ao controle do tempo de aula, entre outros.

Com pertinência, acentuamos que esses saberes foram frutos das reflexões teórico-práticas do professor-educador e dos professores-educandos dentro do programa. Do educador, em seu amadurecimento formacionalacadêmico e experiência pedagógica-escolar e do educando, em formação universitária e práticas iniciais no chão das escolas. São conhecimentos, em 
essência, conferidos pelas traduções das orientações que tomavam vidas no conjunto das atividades mencionadas e faziam-se e refaziam-se em processos contínuos de práticas e reflexões por meio dos círculos de diálogos semanalmente realizados.

Assim, desses encontros dialogados e das experiências vivenciadas surgiram a possibilidade de reafirmação, teórico-prática, de alguns princípios educacionais que no caminhar foram sendo assimilados por todos nós. Pontuamos:

a) A necessidade de uma docência que dialogasse com os alunos e com a realidade dos alunos, isto é, que estabelecesse a comunicação professor-aluno;

b) A importância de conhecer o universo sociocultural do educando (o contexto, a linguagem, os gostos culturais, as experiências, etc.), com a finalidade de ministrar uma aula mais "significativa" (FREIRE; SHOR, 1986);

c) O reconhecimento do saber do aluno e do professor como saberes diferentes e igualmente válidos (FREIRE, 1996; SANTOS, 2002);

d) A valorização da experiência do aluno, a qual tem por base, diversos saberes, sobretudo, o senso comum (FREIRE, 2005; SANTOS, 2002);

e) O estímulo a empatia docente no ministrar das aulas (FREIRE, 1996; MORIN, 2000), entre outros.

São orientações basilares que, como ressaltamos, foram possiveis a partir da adoção da metodologia do diálogo como norteadora da aprendizagem e como propulsora de possibilidades de se conhecer cada vez mais a docência a partir das próprias experiências e das reflexões advindas delas. Nesse sentido, é que as diversas falas dos professores-educandos, nas reuniões do programa, significavam a sua imersão no universo docente, ou seja, não apenas expressavam, oportunamente, o entendimento desse universo que, até então, estava oculto a eles, mas também, o denunciava criticamente. A reflexão, que é resultado de uma prática e que para ela volta, é práxis, é conhecimento crítico de 
um sujeito que está no mundo e com ele interage criticamente. O diálogo como método é caminho para essa interação como pensava o educador Paulo Freire.

\section{Resultados alcançados}

As experiências vivenciadas por meio do programa de iniciação à docência nos possibilitou a construção de diversos saberes educacionais. Além dos conhecimentos auferidos nas reflexões anteriores, ressaltamoso aprendizado teórico através de leituras de textos e análises filmográficas ${ }^{18}$; o amadurecimento das relações coletivas, com o trabalho em grupo e o aprendizado da importância da tomada de decisões em conjunto; um aperfeiçoamento na forma de planejar e ministrar atividades didáticas; a importância do saber dialogal, necessário ao debate democratico, à orientação e à compreensão do outro enquanto ser que aprende; o significado prático com a aproximação dos professores-educandos ao campo de atuação docente, refletindo em um conhecimento mais aprofundado sobre a escola e a sala de aula. Finalmente, o resgate de princípios gerais norteadores de uma prática educativa bem próxima de "um conhecimento prudente para uma vida descente" (SANTOS, 2006).

\section{Considerações finais}

O registro das vivências educativas no programa do PIBID/CS/UFRN e nas escolas parceiras (Escola Professor Anísio Teixeira, Atheneu Norte-rio-grandense e Berilo Wanderley) se insurge contra o "desperdicio das experiências", conforme nos ensina Boaventura de Sousa Santos (2002). Debatemos as experiências educativas vivenciadas por professores da rede pública do Rio Grande do Norte nesses três últimos anos (2014-2016) no que cunhamos de "ensinar e aprender a ser professor".

\footnotetext{
18 Foram acompanhados diversos textos e filmes ao longo dos anos (2014-2016), como exemplos relevantes podemos citar os trabalhos de Paulo Freire (1986; 1996; 2013), Rubem Alves (2004; 2011), Celso Antunes (2013), Edgar Morin (2000; 2003), entre outros. No que se refere ao cinema, cita-se os filmes 5X Favela (2010), Crianças invisiveis (2005), O sal da terra (2015), Tempos modernos (1936).
} 
Entendemos que as práticas educativas, pela metodologia adotada do diálogo, recobraram em muito os ensinamentos de Paulo Freire. Pois, era princípio aos ensinamentos, tanto nas escolas como nas reuniões na universidade, o questionamento e a problematização de temas em uma relação que privilegiava o diálogo entre os participantes. Esses temas eram debatidos a partir de uma questão-problema e inseridos por uma variedade de mecanismos propulsores do diálogo como textos, filme, atividades de teatro, entre outros. 0 diálogo, como acentuado anteriormente em Freire (2006), é, essencialmente, uma relação de "ida e volta" a qual pode inserir-se numa multiplicidade de opiniões de sujeitos e apresentar-se como matriz esclarecedora de realidades múltiplas.

Não necessariamente o diálogo significa consenso ou o debate seja consenso. Aliás, na sociologia o saber não se constrói em um único ponto de vista e nem o sujeito que aprende firma o seu conhecimento, enquanto "verdade", no exato momento da aprendizagem. O sujeito é ser histórico e o saber,o qual se aprende, é construído ao longo do tempo e isso implica, necessariamente, reviravoltas no que foi construído, daí o abandono de ideias, mudanças de opiniões ou cristalizações de pensamentos pelo homem ao longo da história.

Consideramos, também, que as experiências de ensinar e aprender com os futuros professores de sociologia, - em seus significados diversos -, podem ser lidas como contribuições, à formação docente, às diversas instituições educacionais do país, isto é, elas nos possibilitam, em certa medida, a pensar a docência em sua formação no ensino superior, a medida em que põem luz sobre algumas potencialidades da formação de professores por meio do programa PIBID da UFRN.

Essas vivências trouxeram à tona importantes saberes pedagógicos, assentados em autores de reconhecimento nacional e internacional, em especial Freire -, pertinente a uma docência de maior significado social. São saberes que se fundamentaram em etnografias, como forma de conhecer as escolas, leituras de grupos a partir de textos essenciais de Freire e outros autores, saberes técnicos de planejamento escolar e avaliações de experiências em sala de aula, 
entre outros, em um processo contínuo de práticas nas escolas e reflexões através de círculos de diálogos semanais no PIBID.

Em sintese, avaliamos as experiências como bem-sucedidas. Além dos resultados alcançados, que foram salientados por nós anteriormente, ressaltamos como as potencialidades do PIBID para construir ou ressignificar metodologias cresceram e como as capacidades de profissionalização da docência em sociologia aumentaram. Sobre isso, alguns estudos começaram a ser feitos, como artigos, monografias e dissertações sobre o PIBID/CS. Esperamos que isso reflita socialmente em um quadro de professores mais afinados com a sala de aula.

\section{Referências}

5 X FAVELA: AGORA POR NÓS MESMOS. Direção de Manaíra Carneiro et al, Brasil, 2010.

ALMEIDA, J. A. de., et al. Percepções freireana sobre a educação: a escola como tecido de relações humanas. In::ENCONTRO NACIONAL DAS LICENCIATURAS, 5 , 2014, Rio Grande do Norte. Anais... Rio Grande do Norte: UFRN, 2014.

ALVES, Rubem. A casa que educa: as lições que se aprendem "construindo". Rev. Educação, 10 set. 2011. Disponivel em:

<http://www.revistaeducacao.com.br/amyr-klink-casa-educa-coluna-rubemalves/> Acesso em: 13 set. 2016.

ALVES, Rubem. A complicada arte de ver. Folha online, São Paulo, 26 out. 2004. Disponivel em:

<https://www1.folha.uol.com.br/folha/sinapse/ult1063ug47.shtml>. Acesso em: 26 abr. 2016.

ANTUNES, Celso. Professores e professauros: reflexões sobre a aula e práticas pedagógicas diversas. 7. ed. Petrópolis, Rio de Janeiro: Vozes, 2013.

BOAL, Augusto. Teatro do oprimido e outras poéticas políticas. Rio de Janeiro. Civilização Brasileira. 2005.

CASCUDO, Luiz da Câmara. Ateneu norte-rio-grandense, Natal, 1961. Coleção Juvenal Lamartine.

CRIAÇAS INVISÍVEIS. Direção de MehdiCharef, et al. França/Itália, 2005. 
DUARTE, Rosália. Cinema e Educação. Belo Horizonte: Autêntica, 2006.

FONSECA, Cláudia. Quando cada caso NÃO é um caso: pesquisa etnográfica e educação. Revista Brasileira de Educação. n. 10, p. 58-78. 1999.

FREIRE, Paulo. Educação como prática da liberdade. 29. ed. Rio de Janeiro: Paz e Terra, 2006.

FREIRE, Paulo. Pedagogia da autonomia: saberes necessários à prática docente. 34. ed. São Paulo: Paz e Terra, 1996.

FREIRE, Paulo. Pedagogia do oprimido. 43. ed. Rio de Janeiro: Paz e Terra, 2005.

FREIRE, Paulo. Professora sim; tia não: cartas a quem ousa ensinar. 24. ed. Rio de Janeiro: Paz e Terra, 2013.

FREIRE, Paulo; GUIMARÃES, Sérgio. Partir da infância: diálogos sobre educação. São Paulo: Paz e Terra, 2011.

FREIRE, Paulo; GUIMARÃES, Sérgio. Sobre educação: (diálogos). 3. ed. v. 2. São Paulo: Paz e Terra, 2011.

FREIRE, Paulo; SHOR, Ira. Medo e ousadia: o cotidiano do professor. 12. ed. Rio de Janeiro: Paz e Terra, 1986.

GADOTTI, Moacir. A escola e o Professor: Paulo Freire e a paixão de ensinar. São Paulo: Publisher Brasil, 2007.

MARTINS, José de Souza. Sociologia da fotografia e da imagem. 2. Ed. São Paulo: Editora contexto, 2011.

MORIN, Edgar. A cabeça-bem-feita: repensar a reforma, reformar o pensamento. 8. ed. Rio de janeiro: Bertrand Brasil, 2003.

MORIN, Edgar. Os sete saberes necessários à educação do futuro. 2. ed. São Paulo: Cortez; Brasília, DF: UNESCO, 2000.

O SAL DA TERRA: UMA VIAGEM COM SEBASTIÃO SALGADO. Direção: Wim Wenders e Juliano Salgado, Brasil (documentário).

REZENDE, Dannyel Brunno Herculano. Partir do cinema: docência, experiências e saberes em sociologia. In.:CONGRESSO NACIONAL DE EDUCAÇÃO, 3, 2016, Natal. Anais...Campina Grande: Realize Eventos, 2016.

SANTOS, Boaventura de Sousa. A crítica da razão indolente: contra o desperdício da experiência. 4. ed. São Paulo: Cortez, 2002. 
SANTOS, Boaventura de Sousa. A gramática do tempo: para uma nova cultura política. v. 4. 2. ed. São Paulo: Cortez, 2008.

SANTOS, Boaventura de Sousa. Conhecimento prudente para uma vida decente: um discurso sobre as ciências revisitado. 2. ed. São Paulo: Cortez, 2006.

SHIVA, Vandana. Monoculturas da Mente: perspectiva da biodiversidade e da biotecnologia. São Paulo: Gaia, 2003.

SILVA, Leiliane Cosme da; SOUZA, Marília Cirilia Nascimento de; REZENDE, Dannyel Brunno Herculano. Discutindo a sexualidade no ambiente escolar: relato de experiência no colégio estadual do Atheneu Norte-Rio-Grandense (Natal/RN). In.: COLÓQUIO NACIONAL REPRESENTAÇÕES DE GÊNERO E SEXUALIDADE, 11, 2015. Campina Grande. Anais... Campina Grande: Realize Eventos, 2015.

SILVA, Roseli Pereira. Cinema e Educação. São Paulo: Cortez, 2007.

SOUZA, Mauricio Rodrigues de. Por uma educação antropológica: comparando as ideias de Bronislaw Malinowski e Paulo Freire. Revista Brasileira de Educação. v.11, n.33, p. 487-496, 2006.

SPIVAK, Gayatri Chakravorty. Pode o subalterno falar? Belo Horizonte: Editora UFMG, 2010.

TEMPOS MODERNOS. Direção de Charles Chaplin, EUA, 1936.

Recebido: 07 set. 2018

Aceito: 16 out. 2018 